\title{
Wnt blockers inhibit the proliferation of lung cancer stem cells
}

\author{
This article was published in the following Dove Press journal: \\ Drug Design, Development and Therapy \\ 28 April 2015 \\ Number of times this article has been viewed
}

\author{
Xueyan Zhangl,* \\ Yuqing Lou',* \\ Xiaoxuan Zheng' \\ Huimin Wang' \\ Jiayuan Sun' \\ Qianggang Dong ${ }^{2}$ \\ Baohui Han' \\ 'Department of Pulmonary Medicine, \\ Shanghai Chest Hospital, Shanghai \\ Jiaotong University, Shanghai, People's \\ Republic of China; ${ }^{2}$ Section of Cancer \\ Stem Cells, Shanghai Cancer Institute, \\ Shanghai Jiaotong University, Shanghai, \\ People's Republic of China \\ *These authors contributed equally \\ to this work
}

Correspondence: Baohui Han Department of Pulmonary Medicine, Shanghai Chest Hospital, Shanghai Jiaotong University, Huaihai West Road 24I\#, Shanghai 200030,

People's Republic of China

Email hanbaohsh@yeah.net

Qianggang Dong

Section of Cancer Stem Cells, Shanghai Cancer Institute, Shanghai Jiaotong University, Xietu Road 25\#, Shanghai 200000, People's Republic of China Email qianggang_dong@yeah.net
Background: Previous study has confirmed that the occurrence of Wnt pathway activation is associated with risk of non-small-cell lung cancer recurrence. However, whether the pharmacologic blocking of the Wnt signaling pathway could provide therapeutic possibility remains unknown. The aim of the present study was to evaluate the therapeutic functions of the Wnt signaling pathway inhibitor pyrvinium pamoate (PP) on lung cancer stem cells (LCSCs) in vitro.

Methods: Colony formation and sphere culture were performed to enrich LCSCs from three lung cancer cell lines: PC9, SPC-A1, and A549. After confirming stemness by immunofluorescence, $\mathrm{PP}$ was employed for cell viability assay by comparison with three other kinds of Wnt signaling inhibitor: salinomycin, ICG-001, and silibinin. The effect of PP on LCSCs was further verified by colony formation assay and gene expression analysis.

Results: LCSCs were successfully generated by sphere culture from SPC-A1 and PC9 cells, but not A549 cells. Immunofluorescence assay showed that LCSCs could express pluripotent stem cell markers, including NANOG, Oct4, KLF5, and SOX2, and Wnt signaling pathway molecules $\beta$-catenin and MYC. Half-maximal inhibitory concentrations of PP on SPC-A1, PC9, and $\mathrm{A} 549$ were $10 \mathrm{nM}, 0.44 \mathrm{nM}$, and $0.21 \mathrm{nM}$, respectively, which are much lower than those of salinomycin, ICG-001, and silibinin. Moreover, significantly decreased colony formation and downregulation of pluripotent stem cell signaling pathway were observed in lung cancer cells after treatment with PP.

Conclusion: Wnt signaling inhibitor PP can inhibit proliferation of LCSCs, and the Wnt signaling pathway could be considered a promising therapeutic or interventional target in lung adenocarcinoma.

Keywords: pyrvinium pamoate, Wnt signaling pathway, sphere culture, colony formation

\section{Introduction}

Lung cancer, the second most common cancer type in humans, is the most common cause of cancer death in the whole world. In 2008, over 1.6 million people were confirmed with a new diagnosis of lung cancer, comprising approximately $15 \%$ of all newly diagnosed cancers, and 1.4 million people died from lung cancer, which was $18 \%$ of all cancer deaths. ${ }^{1}$ Despite great efforts having been made to explore the therapeutic effect for lung adenocarcinoma, the clinical outcomes of lung adenocarcinoma remain poor in patients. Novel and effective therapies are urgently needed in the current situation.

Cancer stem cells (CSCs), which were initially reported in hematological malignancies, ${ }^{2}$ are a rare population of phenotypically distinct cells displaying unlimited proliferation potential and self-renewal ability. The CSCs cells can also be differentiated and constituted the major tumor population of lung adenocarcinoma. ${ }^{2}$ CSCs are considered important players in tumor development and progression. 
As well as in hematological cancers, the presence of CSCs was also confirmed in several solid tumors, including lung cancer, ${ }^{3}$ and they were proposed as new therapeutic targets for cancer treatment.

Lung CSCs (LCSCs), first described by Carney et $\mathrm{al}^{4}$ were isolated from a variety of cell lines and tumor specimens. ${ }^{5}$ Similar to other CSCs, LCSCs can express biomarkers, including CD44, CD133, and aldehyde dehydrogenase isoform 1 (ALDH1), ${ }^{6}$ and exhibit properties of radioresistance, ${ }^{7}$ chemoresistance, and sphere formation. ${ }^{8}$ A previous study ${ }^{6}$ confirmed that LCSCs are related to the high recurrence rates of lung adenocarcinoma in patients. Moreover, multiple signaling pathways, including those of epidermal growth factor receptor (EGFR), Hedgehog, and Notch, were found to be involved in the regulation of stemness of LCSCs. In 2010, Teng et $\mathrm{al}^{9}$ found an activated Wnt/ $\beta$-catenin pathway in lung cancer cell line A549, which upregulates the stem cell marker Oct4. Shapiro et a ${ }^{10}$ further confirmed that the occurrence of Wnt pathway activation in stage I non-small-cell lung cancer patients was related to the risk of tumor recurrence. However, whether pharmacologic blocking of the Wnt signaling pathway acts as a therapeutic method remains unknown.

In this study, a US Food and Drug Administration (FDA)approved antihelminthics drug targeting Wnt signaling, pyrvinium pamoate (PP), was used to examine the growth inhibition effect on LCSCs in vitro and to explore possible molecular mechanisms.

\section{Materials and methods Cell culture}

Human lung cancer cell lines PC9, SPC-A1, and A549 were purchased from China Academy of Sciences (Shanghai, People's Republic of China). The above cells were cultured in RPMI-1640 or Dulbecco's Modified Eagle's Medium (DMEM) (Hyclone, Logan city, Utah, USA) containing 10\% fetal bovine serum (FBS) (Hyclone). Penicillin (100 U/mL) and streptomycin $(100 \mu \mathrm{g} / \mathrm{mL})$ were added to the DMEM, and the resulting mixture was cultured in a 5\% $\mathrm{CO}_{2}$ incubator at $37^{\circ} \mathrm{C}$.

\section{Sphere formation culture}

Cells were collected from colony formation assay (day 5) (described in Immunofluorescence graph) and suspended in serum-free DMEM/F12 containing 1/100 v/v insulintransferrin-sodium selenite (combination of insulin, transferrin, and selenite) (Sigma-Aldrich Co., St Louis, MO, USA), $20 \mathrm{ng} / \mathrm{mL}$ recombinant EGF (Serotec, Raleigh, NC, USA), and $20 \mathrm{ng} / \mathrm{mL}$ recombinant bFGF (PeproTech, Rocky Hill, NJ, USA). The treated cells were sequentially cultured in a 24-well plate (Corning Incorporated, Corning, NY, USA) at a density of $4 \times 10^{3}$ cells/well. The medium containing the growth factors was replaced every 3 days. After the formation of the sphere (day 8), the cells were collected by centrifugation for further experiments.

\section{Immunofluorescence}

Sphere culture-enriched lung cancer cells $\left(1 \times 10^{6}\right.$ cells $)$ were plated onto slides and incubated overnight. The slides were incubated with paraformaldehyde fixation (4\%) for 30 minutes at $4^{\circ} \mathrm{C}$. Then, the slides were blocked with FBS for 1 hour. The primary antibodies were applied at a 1:100 dilution for 1 hour at room temperature. Phosphate-buffered saline was used as the negative control to replace the primary antibody and to exclude nonspecific binding. The slides were treated with corresponding immunofluorescence-labeled secondary antibodies at $37^{\circ} \mathrm{C}$ for 15 minutes. Cell nucleus was stained with Hoechst 33342 and mounting medium was added before confocal microscopy examination. All the primary antibodies, including Oct4, NANOG, SOX2, KLF5, $\beta$-catenin, and MYC, were purchased from Abcam (Cambridge, UK). The immunofluorescence-labeled secondary antibodies and Hoechst 33342 were purchased from Vector Laboratories, Inc (Burlingame, CA, USA).

\section{Quantitative real-time (RT) polymerase chain reaction assay}

Total cell RNA was isolated from the cells using the TRIzol ${ }^{\circledR}$ RNA extraction kit (Thermo Fisher Scientific, Waltham, MA, USA). The obtained RNA was used to produce the cDNA by using the First Strand cDNA Synthesis Kit (Thermo Fisher Scientific) according to the manufacturer's instructions. Polymerase chain reaction (PCR) was performed using specific primers of related genes (listed in Table 1) and a One Step SYBR $^{\circledR}$ PrimeScript ${ }^{\mathrm{TM}}$ RT-PCR kit (Takara, Dalian, People’s Republic of China). The RT-PCR reaction was performed by utilizing the iQ5 real-time PCR detection system (Bio-Rad Laboratories Inc., Hercules, CA, USA). Furthermore, the expression of the glyceraldehyde 3-phosphate dehydrogenase (GAPDH) gene was assessed simultaneously in all samples, which acted as an internal control. The relative gene expression was calculated by using the $2^{-\Delta \Delta \mathrm{CT}}$ analyzing method.

\section{Cell proliferation}

After preparing the single cell suspension, $1 \times 10^{3}$ cells were seeded in $100 \mu \mathrm{L}$ DMEM solution and then seeded in 
Table I Sequences of the real-time polymerase chain reaction primers

\begin{tabular}{|c|c|c|}
\hline Primer name & Forward primer $\left(5^{\prime}-3^{\prime}\right)$ & Reverse primer $\left(5^{\prime}-3^{\prime}\right)$ \\
\hline Oct4 & GCAATTTGCCAAGCTCCTGAA & GCAGATGGTCGTTTGGCTGA \\
\hline NANOG & AGGCAAACAACCCACTTCT & TCACACCATTGCTATTCTTCG \\
\hline sox2 & ATCACCCACAGCAAATGACA & CAAAGCTCCTACCGTACCACTA \\
\hline KLF5 & ACGTCAATGAAACAGTTCCAGGGC & TTGGGTTGTGAATCGCCAGTTTGG \\
\hline MYC & GCATACATCCTGTCCGTCCA & CAAGAGTTCCGTAGCTGTTCAAG \\
\hline Wnt7b & GGAGGTCCTTTTCCTGGGT & ATATTGCTGTGATGAGGCCC \\
\hline FZDI & ATGAACAAGTTCGGCTTCCA & GGGAACTTCTCGCACTTGAG \\
\hline FZDIO & ACACGTCCAACGCCAGCATG & ACGAGTCATGTTGTAGCCGATG \\
\hline LRP5 & GGCTCGGATGAAGCTAACTG & CAGGATGATGCCAATGACAG \\
\hline CTNNBI & CTCTGGTGGATATGGCCAGGA & CAGATCTGGCAGCCCATCAA \\
\hline GAPDH & GCACCGTCAAGGCTGAGAAC & TGGTGAAGACGCCAGTGGA \\
\hline
\end{tabular}

Abbreviation: GAPDH, glyceraldehyde 3-phosphate dehydrogenase.

96-well plates in quadruplicate overnight. Then, the cells were treated with different concentrations of Wnt signaling pathway antagonists, including LRP6 inhibitor salinomycin (SLM) (Sigma-Aldrich Co.), $\beta$-catenin nuclear transfer inhibitor PP (Sigma-Aldrich Co.), $\beta$-catenin/CREB-binding protein (CBP) transcription complex inhibitor ICG-001 (Selleck, Houston, TX, USA), and milk thistle extract silibinin (Sigma-Aldrich Co.) for 72 hours. Cell viability was determined by Cell Counting Kit-8 (CCK-8) assay at $490 \mathrm{~nm}$ wavelength. The cell proliferation rate was calculated according to the following formula:

$$
\begin{gathered}
\text { Cell proliferation } \\
\text { rate }(\%)
\end{gathered}=\frac{\begin{array}{c}
\text { Experimental group optical } \\
\text { density }(\mathrm{OD}) \text { value }
\end{array}}{\text { Control group OD value }} \times 100 \%
$$

\section{Colony formation assay}

Cells were suspended in $0.3 \%$ agar (Sigma-Aldrich Co.) in culture medium with or without the abovementioned Wnt pathway inhibitors and plated at a density of $1 \times 10^{5}$ cells/dish into a $10 \mathrm{~cm}$ dish, which was preloaded with a thin layer of $1.0 \%$ agar. Cells were kept in media during the assay and monitored for colony formation. After culturing for 7 days, the colony formation was observed. The clones were stained with trypan blue (Sigma-Aldrich Co.) to evaluate colony formation. The clones with more than 50 cells were collected and cells were counted. In a particular setting of colony formation, sphere culture-enriched cells were adjusted to a density of 450 cells/well and seeded into 96-well plates. After culturing the cells for 7 days, the colony formation was assessed by CCK- 8 assay.

\section{Statistical analysis}

Statistical analysis of data was performed by employing the SPSS software package (v 19.0; IBM Corporation,
Armonk, NY, USA). Student's $t$-test was employed for two-group comparison. The one-way ANOVA was employed for multiple-group comparison. Data are presented as mean \pm standard deviation. $P<0.05$ represents a statistically significant difference.

\section{Results Enrichment of LCSCs by colony formation and sphere culture}

As shown in Figure 1A, the holoclone morphology could be found in SPC-A1 and PC9 cells, but not A549 cells, when performing the colony formation assay. The colony formation in PC9 and A549 cells was significantly more compared to SPC-A1 cells (Figure 1B; $P<0.05$ ). Sphere culture was employed to enrich the LCSCs. A large-size cell sphere was found 7 days post-culture (Figure 1C). Cell counting results indicated that the number of SPC-A1 and PC9 cells was $55.0 \times 10^{3}$ cells/well and $30.2 \times 10^{3}$ cells/well, respectively, which indicates a significant difference (Figure 1C; $P<0.05)$. Meanwhile, the number of A549 cells $\left(6.8 \times 10^{3}\right.$ cells/well) was significantly lower compared to the SPC-A1 cells (Figure 1C; $P<0.05$ ). The sphere culture-enriched lung cancer cells were then used for microvolume colony formation assay in a 96-well plate; greater colony formation was found in PC9 cells than in SPC-A1 cells, whereas no colonies were formed in A549 cells (Figure 1D).

\section{Classical Wnt signaling factor expression in LCSCs}

Immunofluorescence staining was employed to determine the cell phenotype. The pluripotent stem cell markers, such as NANOG, Oct4, KLF5, and SOX2, were positively expressed in SPC-A1 and PC9 cells. Moreover, we also found that the Wnt signaling components $\beta$-catenin and MYC were expressed on the sphere culture-enriched cells (Figure 2A and B). 


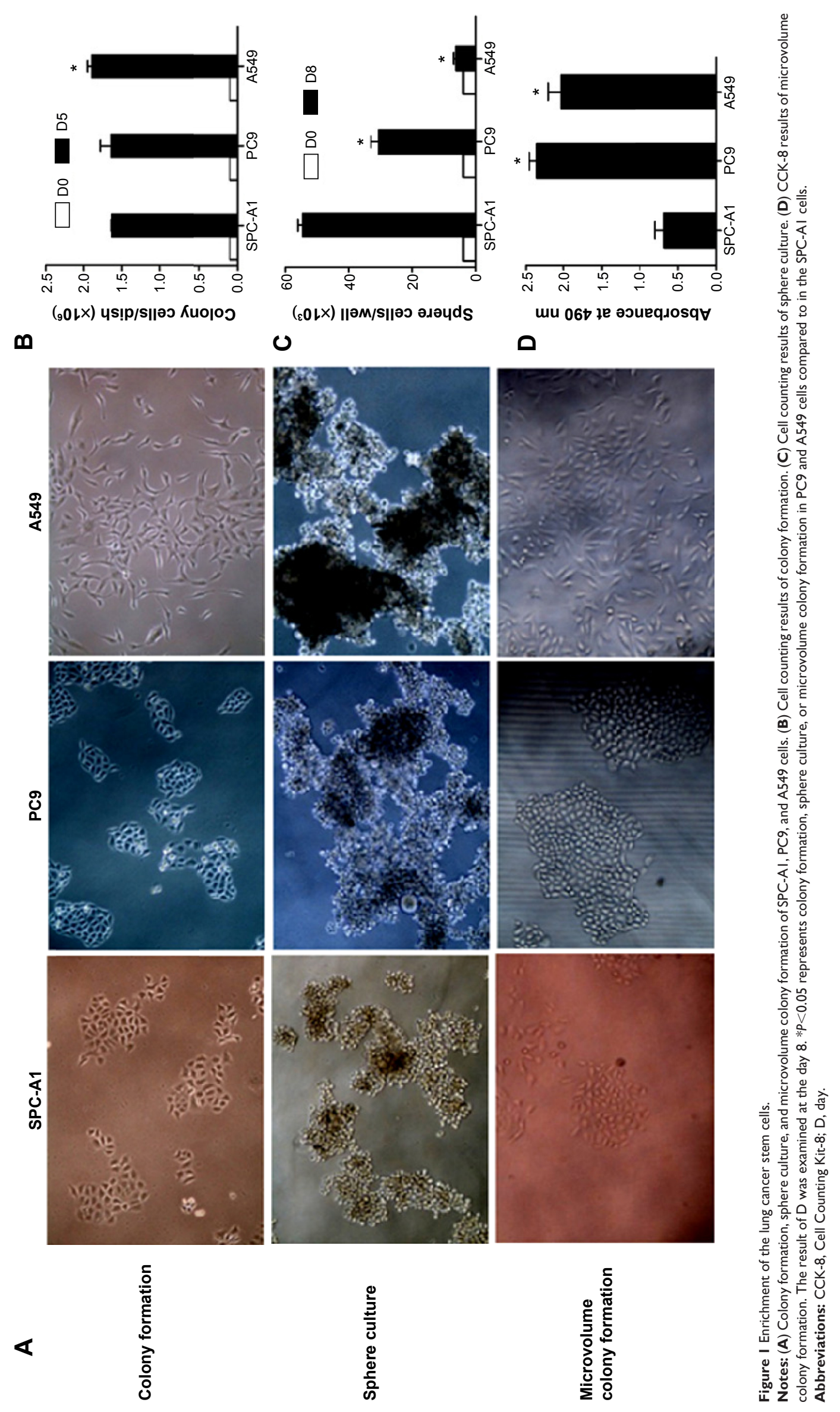


However, the immunofluorescence staining has not been illustrated the positive expressed stem cell markers in A549 cells (data known). In addition, the gene transcription of NANOG, Oct4, KLF5, SOX2, and Wnt signaling pathway factors MYC, Wnt7 $\alpha$, FZD1, FZD10, LRP5, and CTNNB1 was verified using RT-PCR assay. Significant increased transcription of pluripotent stem cell markers and Wnt signaling components was found after sphere culture (Figure 2C-E).

\section{Cell survival analysis of Wnt signaling pathway inhibitors}

We tested the effects of four different Wnt signaling inhibitors on the growth of sphere-cultured cells. The halfmaximal inhibitory concentrations $\left(\mathrm{IC}_{50} \mathrm{~s}\right)$ of these inhibitors are shown in Table 2. SLM (Figure 3A) and ICG-001 (Figure 3B) were used at micromole concentrations, while PP (Figure 3C) was used at a nanomole concentration.

A

SPC-A1

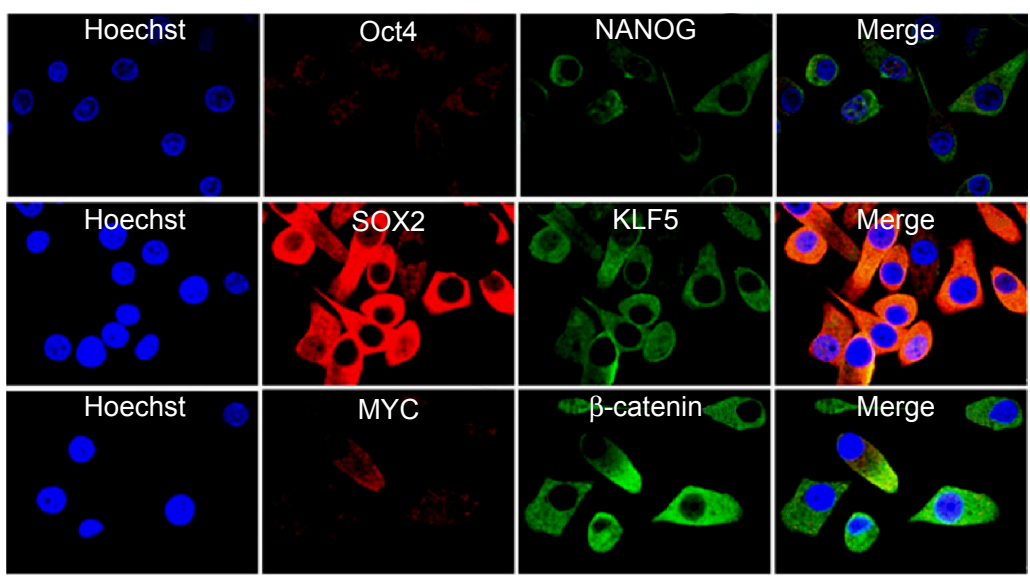

B

PC9
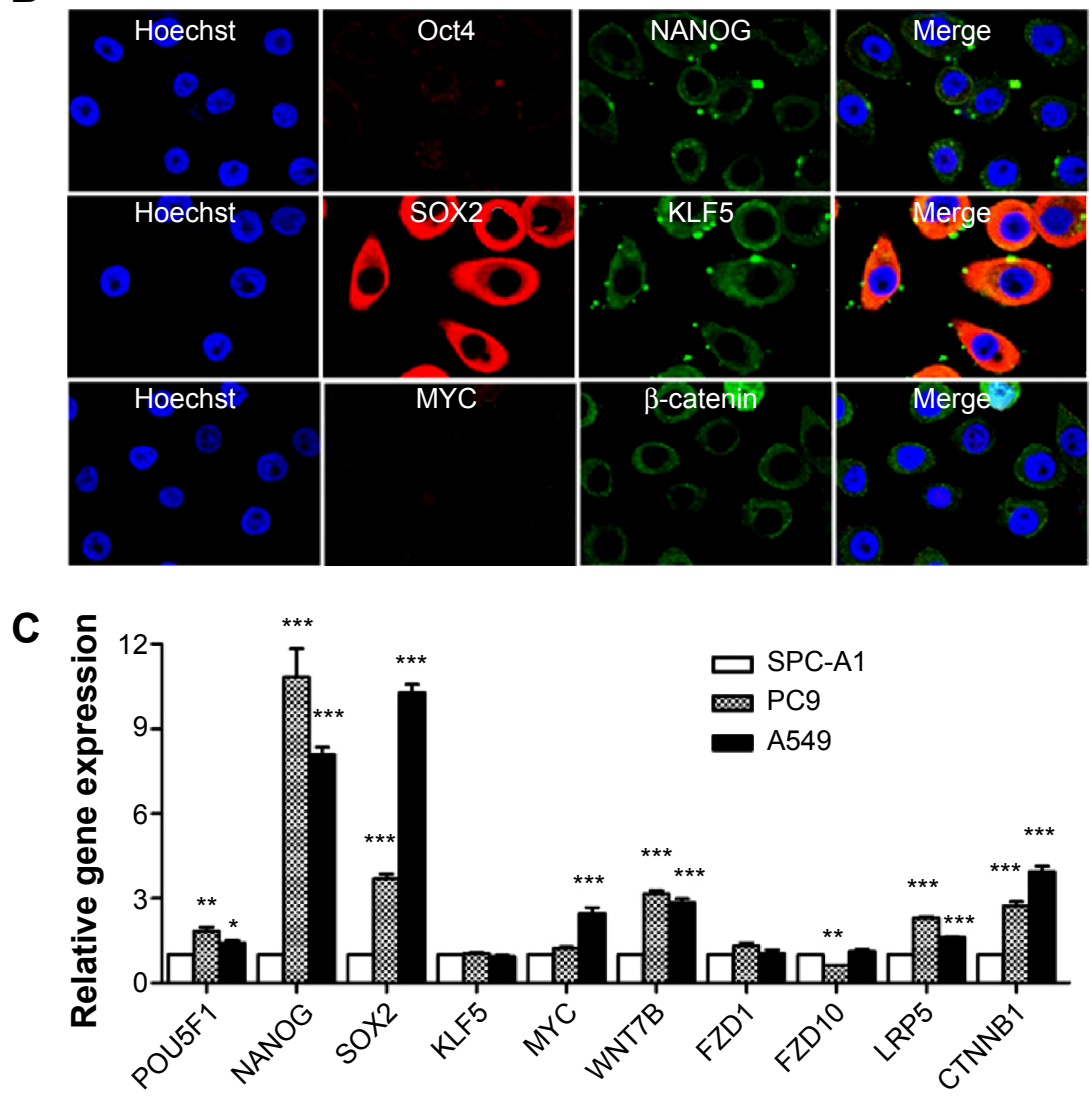

Figure 2 (Continued) 

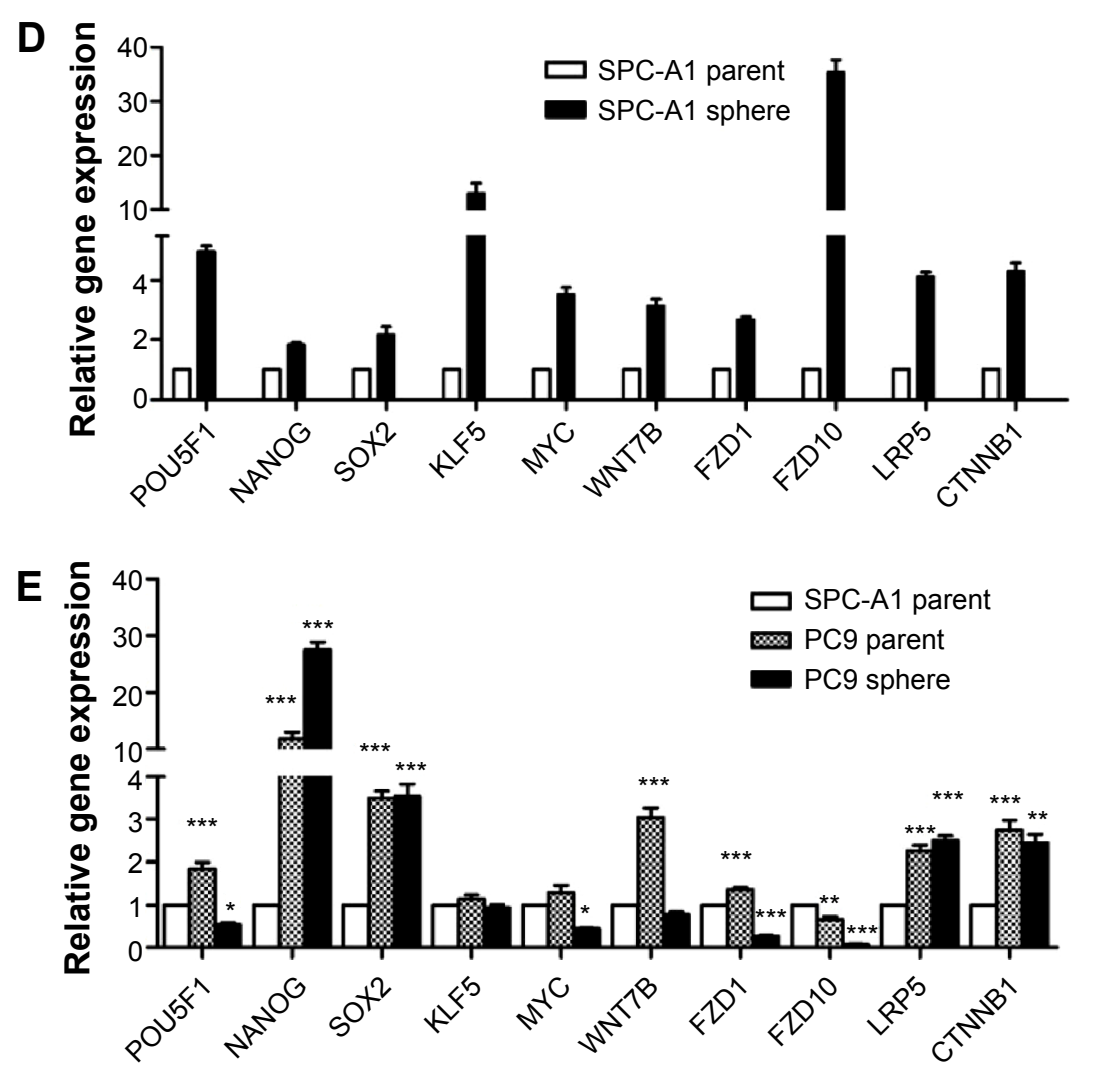

Figure 2 Observation of the classical Wnt signaling factor expression.

Notes: Immunofluorescence characterization of enriched LCSCs from (A) SPC-AI, (B) PC9. The expressions of pluripotent stem cell markers NANOG, Oct4, SOX2, and KLF5, and Wnt signaling components $\beta$-catenin and MYC, were positive on the LCSCs. Quantitative polymerase chain reaction results showed the gene expression pattern of pluripotent stem cell markers and Wnt signaling components. (C) Relative gene expression comparison among three cell lines. (D) Relative gene expression comparison between SPC-AI parent and sphere cells. (E) Relative gene expression comparison among SPC-AI parent, PC9 parent, and PC9 sphere cells. $* P<0.05$, $* * P<0.01$, and $* * * P<0.001$ represent the relative gene expression in PC9 and A549 cells compared to in the SPC-AI cells.

Abbreviation: LCSCs, lung cancer stem cells.

Furthermore, silibinin (Figure 3D) was used at a micromole concentration. The $\mathrm{IC}_{50}$ of PP for sphere-cultured SPC-A1, A549, and PC9 was $10 \mathrm{nM}, 0.44 \mathrm{nM}$, and $0.21 \mathrm{nM}$, respectively (Figure 3).

\section{Anti-proliferation effect of PP by targeting Wnt signaling pathway}

The lung cancer cells were cultured for colony formation and the cells were collected at day 5 and day 7 for cell counting. A significant decrease in cell proliferation after treated with $5 \mathrm{nM} \mathrm{PP}$ was found at the day 7 compared to the day 5

Table $2 I_{50}$ s of the inhibitors

\begin{tabular}{lllll}
\hline Cell type & \multicolumn{1}{l}{ IC } & & \\
\cline { 2 - 5 } & PP & SLM & ICG-00I & Silibinin \\
\hline SPC-AI & $>10 \mathrm{nM}$ & $5.79 \mu \mathrm{M}$ & $65.12 \mu \mathrm{M}$ & $>1,000 \mu \mathrm{M}$ \\
A549 & $0.44 \mathrm{nM}$ & $5.44 \mu \mathrm{M}$ & $7.60 \mu \mathrm{M}$ & $382.70 \mu \mathrm{M}$ \\
PC9 & $0.21 \mathrm{nM}$ & $4.03 \mu \mathrm{M}$ & $2.19 \mu \mathrm{M}$ & $341.70 \mu \mathrm{M}$ \\
\hline
\end{tabular}

Abbreviations: $\mathrm{IC}_{50}$, half-maximal inhibitory concentration; $\mathrm{PP}$, pyrvinium pamoate; SLM, salinomycin.
(Figure 4A). Gene transcription was also determined by utilizing the RT-PCR method, and decreased expression of NANOG, SOX2, Wnt7b, FZD1, LRP5, and CTNNB1 was discovered in all these cell lines (Figure 4B), whereas KLF5 was significantly increased in SPC-A1 (Figure 4C) and PC9 (Figure 4D) cells, and POU5f1 was significantly increased in A549 cells (Figure 4E).

\section{Discussion}

In the present study, we first enriched the LCSCs by colony formation and sphere culture, and confirmed the expression of pluripotent stem cell markers and Wnt signaling components MYC and $\beta$-catenin in LCSCs. Then, in order to verify the function of the Wnt signaling pathway in LCSCs and to seek therapeutic agents, four different kinds of Wnt signaling inhibitors were employed to test the anti-proliferation effect. We found that PP efficiently inhibits LCSC proliferation in vitro at a dose below $10 \mathrm{nM}$ and might have the potential to be used as a novel therapeutic agent to achieve desired clinical outcome in lung cancer patients. 
A

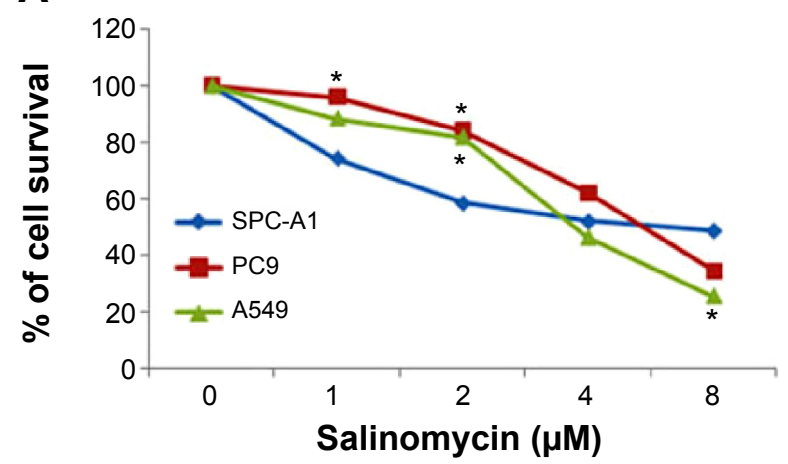

C

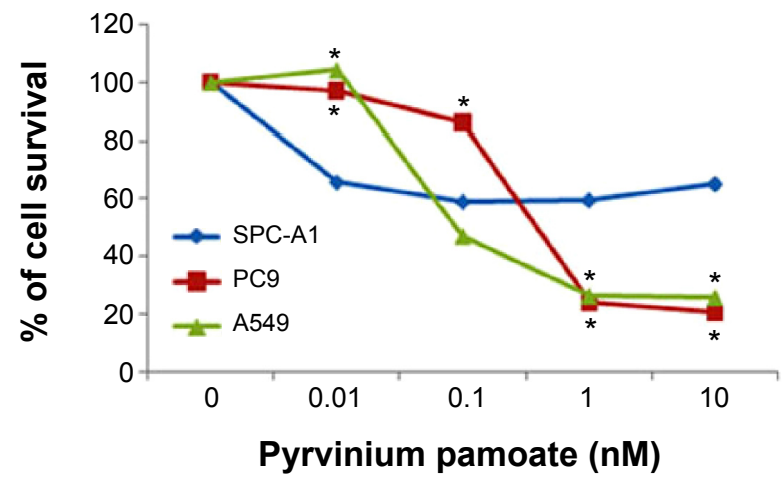

B

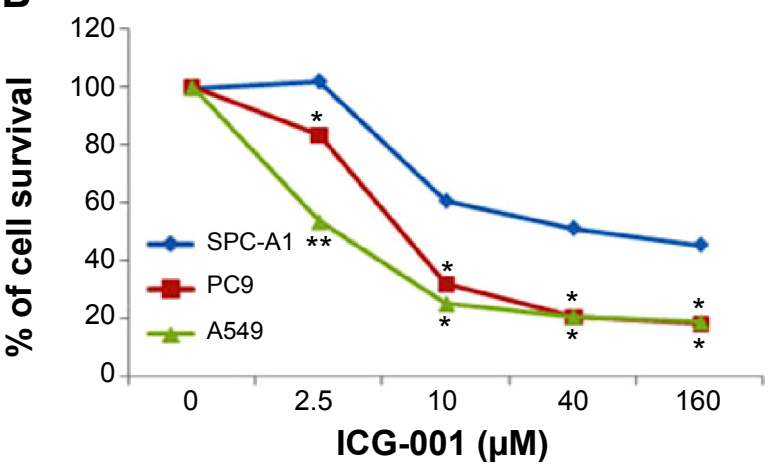

D

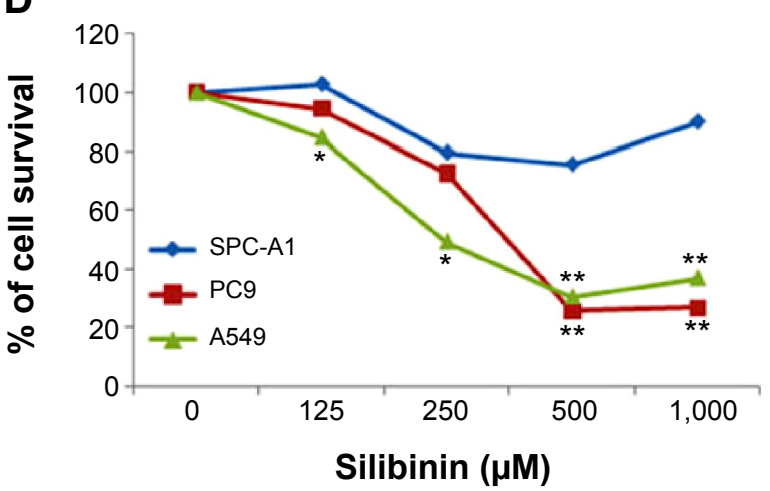

Figure 3 Cell survival analysis using four different Wnt signaling inhibitors.

Notes: (A) Salinomycin; (B) ICG-00I; (C) pyrvinium pamoate; (D) silibinin. ${ }^{*} P<0.05$ and $* * P<0.0$ I represent the cell survival percentage in PC9 and A549 cells compared to in the SPC-AI cells.

The Wnt/ $\beta$-catenin signaling pathway is one of the most critical signaling transduction pathways in cell tumorigenesis, development, proliferation, and progression. ${ }^{11}$ The Wnt $/ \beta$ catenin signaling pathway has become a hot topic in tumor research. In recent years, $\mathrm{Wnt} / \beta$-catenin signaling pathway study has developed to the stage of progenitor and stem cell maintenance in some adult individual tissues, such as blood, muscle, skin, gut, nervous system, and prostate. ${ }^{12}$ We observed the expression of Wnt signaling components in enriched LCSCs from lung cancer cells. We found that the Wnt signaling inhibitors, including SLM, ICG-001, PP, and silibinin, can effectively inhibit the growth of LCSCs in vitro.

A great deal of study has been undertaken to discover compounds or drugs that could specifically target CSCs. Some compounds have been discovered that could effectively target LCSCs. SLM is the first reported drug that used to therapy the Coccidia parasites in chickens. SLM is a potassium channel inhibitor, which can target CSCs in tumors, such as those found in leukemia, breast cancer, and other cancers. ${ }^{13}$ Wang suggested that SLM could also be used in the treatment of LCSCs. ${ }^{14}$ ICG-001 is a $\beta$-catenin/CBP inhibitor that can bind to the N-terminus of CBP. ICG-001 can also effectively attenuate the survivin expression in tumors. ${ }^{15}$ ICG-001 has shown the ability to kill CSCs in neuroblastoma cell lines ${ }^{16}$ and hepatoblasts. ${ }^{17}$ Silibinin, a naturally occurring flavonoid produced by milk thistle, possesses antioxidant and anti-inflammatory activities. ${ }^{18}$ Wang et al showed that silibinin could inhibit the maintenance and proliferation of CSCs in colorectal tissues via GSK-3 $\beta$-related pathways, ${ }^{19}$ and it may be involved in a mechanism of Wnt signaling regulation. SLM, ICG-001, and silibinin were employed here for comparison with PP. We found sphere-cultured A549 and PC9 cells were sensitive to all the inhibitors, while sphere-cultured SPC-A1 cells were only sensitive to SLM and ICG-001. This may be attributed to the participation of Wnt/GSK-3 $\beta$ in regulation of LCSCs in the PC9 and A549 cells, but not in the SPC-A1 cells. Therefore, further studies are needed to assess the detailed pathway regulation in different lung cancer cell lines.

Moreover, all three of the inhibitors (SLM, ICG-001, and silibinin) were used at a micromole-level dose, while PP could work at a nanomole-level dose, which was significantly lower than those of SLM, ICG-001, and silibinin. PP is a quinoline-derived cyanine dye, which was officially approved by the FDA for its antihelminthic characteristics in 
A

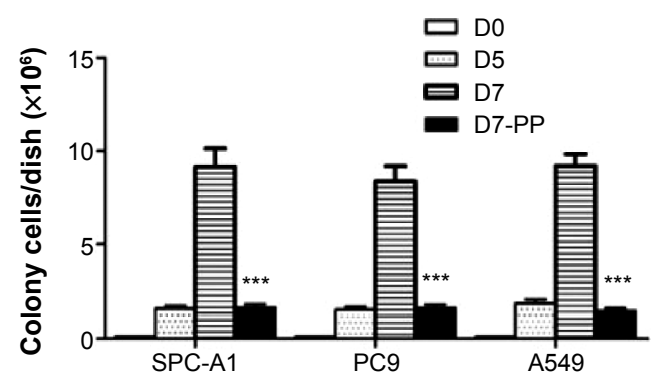

C

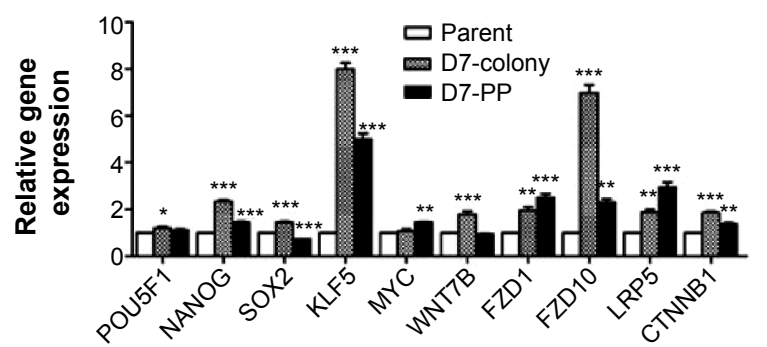

B

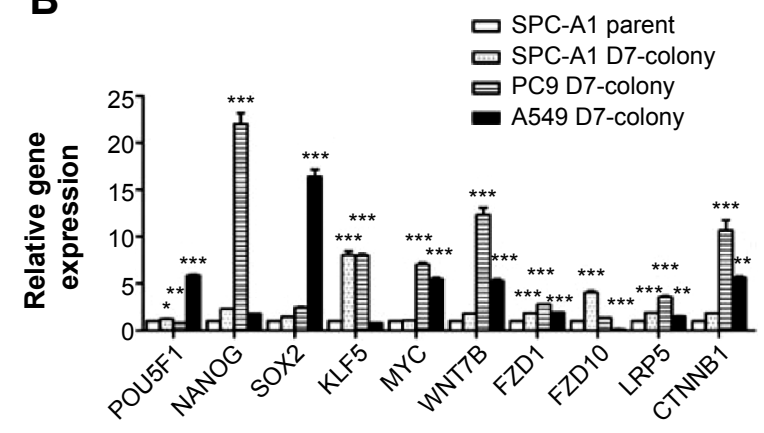

D

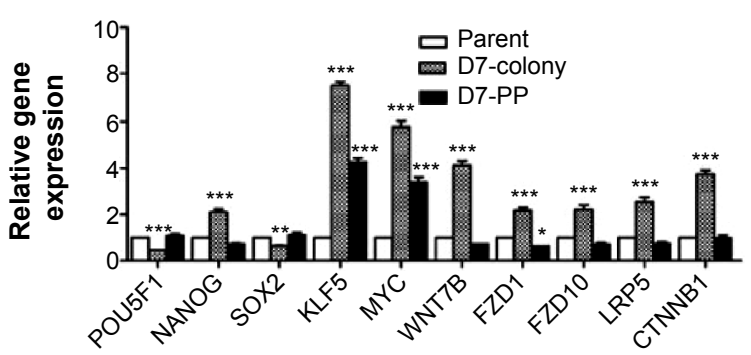

E

A549

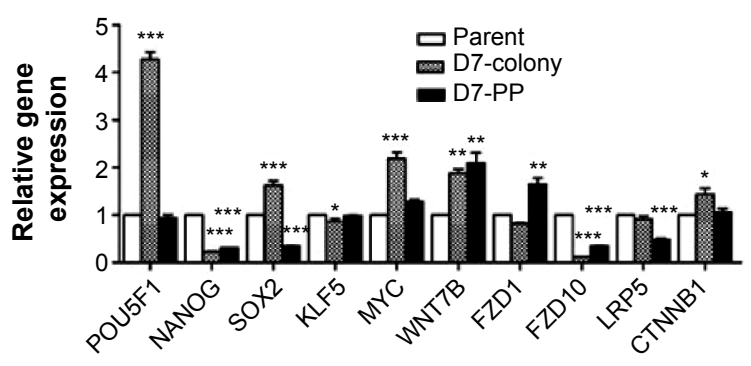

Figure 4 The effect of PP on the colony formation and gene expression of PC9, SPC-AI, and A549 cells.

Notes: (A) PP significantly decreased the colony formation in PC9, SPC-AI, and A549 cells. Quantitative polymerase chain reaction results showed the gene expression pattern of pluripotent stem cell markers and Wnt signaling components in three cell lines. Relative gene expression of (B) cells collected at D7 of colony formation, (C) SPCAl cells with or without PP incubation, (D) PC9 cells with or without PP incubation, and (E) A549 cells with or without PP incubation. $* P<0.05$, $* * P<0.0$ I, and $* * * P<0.00$ I represent the colony formation or relative gene expression in D7-colony or D7-PP group compared to in the parent group.

Abbreviations: D, day; PP, pyrvinium pamoate.

the $1950 \mathrm{~s} .{ }^{20}$ Some authors have reported PP to have a therapeutic function against animal-like protists, such as Cryptosporidium parvum, ${ }^{21}$ Plasmodium falciparum, ${ }^{22}$ and others. In recent years, a few studies proved that PP could delay or inhibit tumor cell proliferation in cancer models, including models of pancreatic cancer ${ }^{23}$ and colon cancer. ${ }^{24}$

PP has been used in clinic for about 50 years, but the pharmacological mechanisms are not yet fully clarified. However, in the last 10 years, more and more researchers have studied PP in tumor therapy. Saraswati et al ${ }^{25}$ discovered that PP could inhibit the Wnt signaling transduction pathway by activating casein kinase $1 \alpha(\mathrm{CK}-1 \alpha)$. Wnt signaling-related proteins or genes have been studied in recent years with formation assay, including the expression of MYC protein and the activity of TOP-luciferase. ${ }^{6}$ In vivo, Wnt signaling pathway inhibitors were examined employing classic Xenopus secondary axis formation analysis. ${ }^{26}$ Gao et $\mathrm{al}^{27}$ found that CK- $1 \alpha$ could be directly targeted and activated by PP. What is known so far is that $\mathrm{CK}-1 \alpha$ is a critical kinase that can phosphorylate $\beta$-catenin. Further studies to verify expression levels of CK-1 $\alpha$ could determine whether it is a target protein of PP in LCSCs.

\section{Conclusion}

PP was found to be able to selectively kill LCSCs and showed effective anti-tumor proliferation activity in vitro. However, further studies on decreasing the toxicity of PP and determining the target protein and signaling pathway should be performed before PP can be considered a therapeutic agent in lung adenocarcinoma. 


\section{Acknowledgment}

The present work received a grant from the Natural Science Foundation of Shanghai (number 13ZR1438600).

\section{Disclosure}

The authors report no conflicts of interest in this work.

\section{References}

1. Jemal A, Bray F, Center MM, Ferlay J, Ward E, Forman D. Global cancer statistics. CA Cancer J Clin. 2011;61(2):69-90.

2. Clarke MF, Dick JE, Dirks PB, et al. Cancer stem cells - perspectives on current status and future directions: AACR Workshop on cancer stem cells. Cancer Res. 2006;66(19):9339-9344.

3. Eramo A, Lotti F, Sette G, et al. Identification and expansion of the tumorigenic lung cancer stem cell population. Cell Death Differ. 2008;15(3): 504-514.

4. Carney DN, Gazdar AF, Bunn PA Jr, Guccion JG. Demonstration of the stem cell nature of clonogenic tumor cells from lung cancer patients. Stem Cells. 1982;1(3):149-164.

5. Fang S, Wang Z. EGFR mutations as a prognostic and predictive marker in non-small-cell lung cancer. Drug Des Devel Ther. 2014;8: $1595-1611$.

6. Okudela K, Woo T, Mitsui H, Tajiri M, Masuda M, Ohashi K. Expression of the potential cancer stem cell markers, CD133, CD44, ALDH1, and $\beta$-catenin, in primary lung adenocarcinoma - their prognostic significance. Pathol Int. 2012;62(12):792-801.

7. Xia P, Gou WF, Wang JJ, et al. Distinct radiosensitivity of lung carcinoma stem-like side population and main population cells. Cancer Biother Radiopharm. 2013;28(6):471-478.

8. Morrison BJ, Steel JC, Morris JC. Sphere culture of murine lung cancer cell lines are enriched with cancer initiating cells. PLoS One. 2012; 7(11): 49752.

9. Teng Y, Wang X, Wang Y, Ma D. Wnt/beta-catenin signaling regulates cancer stem cells in lung cancer A549 cells. Biochem Biophys Res Commun. 2010;392(3):373-379.

10. Shapiro M, Akiri G, Chin C, et al. Wnt pathway activation predicts increased risk of tumor recurrence in patients with stage I nonsmall cell lung cancer. Ann Surg. 2013;257(3):548-554.

11. Holland JD, Klaus A, Garratt AN, Birchmeier W. Wnt signaling in stem and cancer stem cells. Curr Opin Cell Biol. 2013;25(2):254-264.

12. He B, Barg RN, You L, et al. Wnt signaling in stem cells and non-smallcell lung cancer. Clin Lung Cancer. 2005;7(1):54-60.

13. Gupta PB, Onder TT, Jiang G, et al. Identification of selective inhibitors of cancer stem cells by high-throughput screening. Cell. 2009;138(4): 645-659.
14. Wang Y. Effects of salinomycin on cancer stem cell in human lung adenocarcinoma A549 cells. Med Chem. 2011;7(2):106-111.

15. Kim YM, Ma H, Oehler VG, et al. The gamma catenin/CBP complex maintains survivin transcription in $\beta$-catenin deficient/depleted cancer cells. Curr Cancer Drug Targets. 2011;11(2):213-225.

16. Vangipuram SD, Buck SA, Lyman WD. Wnt pathway activity confers chemoresistance to cancer stem-like cells in a neuroblastoma cell line. Tumour Biol. 2012;33(6):2173-2183.

17. Mavila N, James D, Utley S, et al. Fibroblast growth factor receptormediated activation of AKT- $\beta$-catenin-CBP pathway regulates survival and proliferation of murine hepatoblasts and hepatic tumor initiating stem cells. PLoS One. 2012;7(11):e50401

18. Hagelgans A, Nacke B, Zamaraeva M, Siegert G, Menschikowski M. Silibinin down-regulates expression of secreted phospholipase A2 enzymes in cancer cells. Anticancer Res. 2014;34(4):1723-1729.

19. Wang JY, Chang CC, Chiang CC, Chen WM, Hung SC. Silibinin suppresses the maintenance of colorectal cancer stem-like cells by inhibiting PP2A/AKT/mTOR pathways. J Cell Biochem. 2012;113(5): 1733-1743.

20. Smith TC, Kinkel AW, Gryczko CM, Goulet JR. Absorption of pyrvinium pamoate. Clin Pharmacol Ther. 1976;19(6):802-806.

21. Hempelmann E. Hemozoin biocrystallization in Plasmodium falciparum and the antimalarial activity of crystallization inhibitors. Parasitol Res. 2007;100(4):671-676.

22. Downey AS, Chong CR, Graczyk TK, Sullivan DJ. Efficacy of pyrvinium pamoate against Cryptosporidium parvum infection in vitro and in a neonatal mouse model. Antimicrob Agents Chemother. 2008;52(9): 3106-3112.

23. Esumi H, Lu J, Kurashima Y, Hanaoka T. Antitumor activity of pyrvinium pamoate, 6-(dimethylamino)-2-[2-(2,5-dimethyl-1-phenyl1H-pyrrol-3-yl)ethenyl]-1-methyl-quinolinium pamoate salt, showing preferential cytotoxicity during glucose starvation. Cancer Sci. 2004;95(8):685-690.

24. Yu DH, Macdonald J, Liu G, et al. Pyrvinium targets the unfolded protein response to hypoglycemia and its anti-tumor activity is enhanced by combination therapy. PLoS One. 2008;3(12):e3951.

25. Saraswati S, Alfaro MP, Thorne CA, Atkinson J, Lee E, Young PP. Pyrvinium, a potent small molecule Wnt inhibitor, promotes wound repair and post-MI cardiac remodeling. PLoS One. 2010;5(11): e15521.

26. Thorne CA, Hanson AJ, Schneider J, et al. Small-molecule inhibition of Wnt signaling through activation of casein kinase $1 \alpha$. Nat Chem Biol. 2010;6(11):829-836.

27. Gao ZH, Seeling JM, Hill V, Yochum A, Virshup DM. Casein kinase I phosphorylates and destabilizes the beta-catenin degradation complex. Proc Natl Acad Sci U S A. 2002;99(3):1182-1187.

\section{Publish your work in this journal}

Drug Design, Development and Therapy is an international, peerreviewed open-access journal that spans the spectrum of drug design and development through to clinical applications. Clinical outcomes, patient safety, and programs for the development and effective, safe, and sustained use of medicines are a feature of the journal, which

\section{Dovepress}

has also been accepted for indexing on PubMed Central. The manuscript management system is completely online and includes a very quick and fair peer-review system, which is all easy to use. Visit http://www.dovepress.com/testimonials.php to read real quotes from published authors. 